\title{
Surface Properties of Poplar Wood after Heat Treatment, Resin Impregnation, or Both Modifications
}

\author{
Shuai Cao, ${ }^{\mathrm{a}}$ Jiabin Cai, ${ }^{\mathrm{a}, \mathrm{b}, *}$ Meihui Wu, ${ }^{\mathrm{a}}$ Nan Zhou, ${ }^{\mathrm{c}}$ Zhenhua Huang, ${ }^{\mathrm{d}}$ Liping Cai,,${ }^{\mathrm{a} d}$ \\ and Yinglu Zhang ${ }^{\text {a }}$
}

To investigate the surface properties of different modified poplar (Populus tomentosa Carr.) wood samples, the color, surface roughness, and wettability of untreated poplar wood (control) and poplar modified via heat treatment, resin impregnation, and impregnation combined heat treatment were analyzed and compared in this study. The impregnant used in the test was a modified urea-formaldehyde resin with a low molecular weight and low viscosity. The results showed that the lightness of the samples was sorted in order as follows: the control was lighter than the resin impregnated sample, which was lighter than the impregnation combined heat treatment sample, which was lighter than the heat treatment sample. The surface of the control samples was relatively smooth, while after the impregnation, heat, and impregnation combined heat treatments, the $R_{a}$ and $R_{z}$ values increased, which indicated increased surface roughness due to the modifications. Among them, the heat-treated samples had the roughest surface, and the surface roughness of the impregnation combined heat treated samples at $160^{\circ} \mathrm{C}$ had no major difference from the resin impregnated sample. The wettability of the samples decreased after heat treatment and increased after impregnation combined heat treatment. It was concluded that after the modification treatments, the color of the wood became darker, and the surface roughness and hydrophobicity increased.

Keywords: Heat treatment; Impregnation; Impregnation combined heat treatment; Surface properties

Contact information: a: Nanjing Forestry University, Nanjing 210037 China; $b$ : Co-Innovation Center of Efficient Processing and Utilization of Forest Resources, Nanjing 210037 China; c: Fuyang Jinmu Arts and Crafts Co. Ltd, Fuyang 236000 China; d: Department of Mechanical Engineering, University of North Texas, Denton, TX 76207 USA; *Corresponding author: nldfloor@163.com

\section{INTRODUCTION}

Poplar is a fast-growing plantation tree species; however, its density, mechanical properties, and dimensional stability are relatively inferior to those of natural wood species. In order to improve the properties of the fast-growing timber, researchers have conducted many studies and used different modification techniques. High-temperature (usually 160 to $220{ }^{\circ} \mathrm{C}$ ) heat treatment (HT) technology is the most environmentally friendly physical modification method widely used to improve the dimensional stability of wood, but the mechanical strength of wood is reduced by it. Resin impregnation (IMPG) modification not only can enhance the mechanical properties of wood, e.g., its density, bending strength, hardness, etc., but it also improves its flame retardancy, bioerosion resistance, as well as other applicability properties (Huang et al. 2013; Qin et al. 2015; Sandberg et al. 2017; Cai et al. 2020). Both impregnation and high-temperature heat treatment can improve certain properties of wood. In addition, the changes in color, surface roughness, wettability, and other surface properties of wood due to impregnation and heat treatment have been widely 
accepted by wood industry and market. The color is an important indicator that reflects the visual characteristics of the wood surface. Therefore, it is of great significance to carry out research on the effect of modified wood's color on its application in the furniture, flooring, and decoration industries. However, these single modification methods cannot improve all the previously mentioned properties. The modification lead to certain deficiencies, such that the modified wood often cannot meet the requirements for an application. Therefore, in order to obtain modified wood with better properties, it is desired to seek an impregnation combined heat treatment process to expand the application range of fastgrowing wood.

There has been related research on the modification treatment of impregnation combined with heat treatment, but the research is still in its infancy. Baysal et al. (2014) studied some mechanical properties such as modulus of rupture (MOR) and some physical properties such as glossiness, color, surface roughness, and water absorption (WA) of adolit-KD 5 impregnated and then heat treated of Scots pine (Pinus sylvestris L.) wood specimens, They found that adolit-KD 5 treatment before heat treatment caused decreases in the glossiness and color. Heat treatment induced a strong decrease of luminance (darkening). Moreover, increasing treatment temperature and duration, resulted in decreasing values of MOR, WA, glossiness, and surface roughness. Turkay et al. (2016) investigated mechanical properties such as the modulus of rupture (MOR) and compression strength parallel to grain (CSPG) of impregnated by Wolmanit CX-8 (WCX-8) and Celcure AC-500 (CAC500) and heat-treated Oriental beech (Fagus orientalis Lipsky) wood. It was found that both impregnation and heat treatment decreased the MOR and CSPG of Oriental beech wood and higher treatment duration and temperature resulted in lower MOR and CSPG of Oriental beech. Liu et al. (2013) investigated the influence of melamine-ureaformaldehyde (MUF) resin impregnation combined with heat treatment on the dimensional stability and mechanical properties of eucalyptus. It was found that the dimensional stability and mechanical properties of the MUF resin combined heat treatment at a temperature of $240{ }^{\circ} \mathrm{C}$ were better than the properties of the heat treated only wood. Xu et al. (2015) used different heat treatment processes to treat timbers impregnated by PF resin and found that the heat treatment improved the dimensional stability of timbers impregnated with PF resin. In addition, the mechanism of the reduction of the hygroscopicity was studied using infrared spectroscopy. Quan et al. (2017) found that the heat treatment temperature had a greater impact on the hygroscopicity and dimensional stability of impregnated poplar wood than the heat treatment time. A study by Lahtela and Kärki (2016) showed that the proper heat treatment of impregnated timber can improve the mechanical properties. It was believed that the modified wood via combined treatments had the potential to be used in outdoor structures and furniture.

Studies on wood modification primarily focus on basic physical properties, e.g., the hygroscopicity, dimensional stability, and macroscopic mechanical properties. Limited studies on the surface properties of the modified wood have been completed. In addition, the wood samples used in experiments are mostly small sized (with the size ranging from $50 \mathrm{~mm} \times 50 \mathrm{~mm} \times 10 \mathrm{~mm}$ to $400 \mathrm{~mm} \times 120 \mathrm{~mm} \times 25 \mathrm{~mm}$ ), which is quite different from the actual situation in industrial production (Sivrikaya et al. 2019). Therefore, in this experiment, the surface properties of industrial scaled specimens were examined using industrial equipment in order to provide further guidance for the actual manufacturing. 


\section{EXPERIMENTAL}

\section{Materials and Equipment}

The wood species used in this study was poplar (Populus tomentosa Carr.) with a diameter at breast height greater than $30 \mathrm{~cm}$ (purchased from Siyang, China). The sawn timber with a size of $2400 \mathrm{~mm} \times 100 \mathrm{~mm} \times 28 \mathrm{~mm}(\mathrm{~L} \times \mathrm{W} \times \mathrm{T})$ was first kiln-dried until the moisture content reached $12 \%$, and then it was surface planed to a thickness of $22 \mathrm{~mm}$. A total of 150 timber samples were selected with straight grains and no defects, which were numbered as \#1, \#2, \#3... \#150 sequentially.

The impregnant used in the test was a modified urea-formaldehyde resin with a low molecular weight (less than $500 \mathrm{~g} / \mathrm{mol})$ and low viscosity $(1.5 \mathrm{mPa} \cdot \mathrm{s}$ at a temperature of $23{ }^{\circ} \mathrm{C} \pm 0.5{ }^{\circ} \mathrm{C}$ via the rotary viscometer method), and a solid content of $19.56 \%$ (the original solid content was approximately $50 \%$ ), which was independently developed and produced by Fuyang Jinmu Arts and Crafts Co. Ltd. (Anhui, China). The reaction raw materials primarily included urea, ammonia, formaldehyde, melamine, and other ingredients. The primary performance indicators were tested according to GB/T standard 14074 (2017).

To reduce the differences among the test groups, two boards with a length of 330 $\mathrm{mm}$ were cut by band saw from all timber samples. One board was unmodified, while the other board was heat-treated at a temperature of $180^{\circ} \mathrm{C}$ for $3 \mathrm{~h}$. The remaining timber (with a length of $1740 \mathrm{~mm}$ ) was first impregnated with the modified urea-formaldehyde resin at a vacuum and then kiln-dried and cut into four equal pieces. One of which was not processed as a control, while the other three were heat-treated at a temperature of 160, 180, and $200{ }^{\circ} \mathrm{C}$ for $3 \mathrm{~h}$, respectively. Therefore, there were 6 groups of samples in this experiment, including the control, heat treatment at a temperature of $180{ }^{\circ} \mathrm{C}$, resin impregnation, and impregnation combined with heat treatment at 3 different temperatures (Table 2).

\section{Methods}

Impregnation combined heat treatment process

The timber samples were impregnated according to LY/T standard 2407 (2015) and the production process of the enterprise. The first step of the impregnation process was to vacuum the dried poplar timber at $-0.08 \mathrm{MPa}$ for $30 \mathrm{~min}$ in a vacuum impregnated pressure tank. Then, the dried timber was filled with the impregnation liquid in a vacuum state, and the impregnation pressure was increased to $3.0 \mathrm{MPa}$ and maintained for $1 \mathrm{~h}$. After that, the timber samples were taken out and the surface liquid was removed, the pressure was released, and the remaining impregnating liquid was discharged. After $3 \mathrm{~d}$, the impregnated timbers were dried again to a moisture content of $12 \%$; the drying period was $23 \mathrm{~d}$.

\section{Color measurement}

The samples of control, heat treatment at a temperature of $180{ }^{\circ} \mathrm{C}$, resin impregnation, and impregnation combined with heat treatment at 3 different temperatures were respectively processed into samples with a size of $330 \mathrm{~mm} \times 100 \mathrm{~mm} \times 20 \mathrm{~mm}$. Each group had 10 samples, with a total of 60 samples. The color of the wood surface was measured with a colorimeter according to the CIE wood color characterization method promulgated by the International Commission on Illumination (CIE). The CIELab System was used for color evaluation. A chroma meter (CR-400, Konica Minolta, Tokyo, Japan) was used to measure the $L^{*}, a^{*}$, and $b^{*}$ parameters at four specific positions $(6 \mathrm{~cm}$ between 
each two points) on the tangential surface of each sample after regular intervals, and the average values were calculated. The $L^{*}$ denotes lightness (+ denotes brighter and - denotes darker), $a^{*}$ denotes the red-green index (+ denotes reddish and - denotes greenish), and $b^{*}$ denotes the yellow-blue index (+ denotes yellowish and - denotes bluish). The $\Delta L^{*}, \Delta a^{*}$, $\Delta b^{*}$ parameters and the $\Delta E$ were calculated according to Eqs. 1 through 4 ,

$$
\begin{aligned}
& \Delta L^{*}=L_{t}{ }^{*}-L_{i}{ }^{*} \\
& \Delta a^{*}=a_{t}{ }^{*}-a_{i}{ }^{*} \\
& \Delta b^{*}=b_{t}{ }^{*}-b_{i}{ }^{*} \\
& \Delta E=\sqrt{\left(\Delta L^{*}\right)^{2}+\left(\Delta a^{*}\right)^{2}+\left(\Delta b^{*}\right)^{2}}
\end{aligned}
$$

where the $L_{i}^{*}, a_{i}{ }^{*}$ and $b_{i}{ }^{*}$ are the lightness, red-green index, and yellow-blue index of the untreated wood, respectively, $L_{t}^{*}, a_{t}^{*}$, and $b_{t}^{*}$ are the lightness, red-green index, and yellow-blue index of the modified wood, and $\Delta L^{*}, \Delta a^{*}, \Delta b^{*}$, and $\Delta E$ are the differences in the brightness, red-green index, yellow-blue index, and total color change, respectively (Ding et al. 2017).

\section{Surface roughness measurement}

The samples of control, heat treatment at a temperature of $180{ }^{\circ} \mathrm{C}$, resin impregnation, and impregnation combined with heat treatment at 3 different temperatures were respectively processed into specimens with a size of $50 \mathrm{~mm} \times 50 \mathrm{~mm} \times 20 \mathrm{~mm}$. Each group had 10 samples, with a total of 60 samples. In this experiment, one side of the sample surface was manual-planed, and the other side was sanded with 320\# sandpaper and then 400\# sandpaper. The roughness after the hand-planing was measured via a TR110 portable surface roughness meter (Shanghai Double Produced by Asahi Electronics Co., Ltd.) (indicating error less than or equal to $\pm 15 \%$ ). The sampling length was $L=2.5 \mathrm{~mm}$ and the evaluation length was $5 L=12.5 \mathrm{~mm}$. The surface roughness after sanding was measured via a JB-4C precision roughness meter (Shanghai Taiming Optical Instrument Co., Ltd.) (indicating error less than or equal to $\pm 5 \%$ ).

Referring to GB/T standard 12472 (2003) and GB/T standard 1031 (2009), 6 areas along the transverse direction of the tangential surface, after the manual planing and sanding, were measured (the probe of the measuring head was perpendicular to the grain direction), and the average surface roughness value was then calculated. The sampling length was $L=0.8 \mathrm{~mm}$ and the evaluation length was $5 L=4 \mathrm{~mm}$. The measurements were randomized relative to their order to make sure that their conclusions were not affected by the gradual wearing out or filling of the sand paper. In general, the average roughness $\left(R_{\mathrm{a}}\right)$ and average peak-valley height $\left(R_{\mathrm{z}}\right)$ can comprehensively represent the roughness of a wood surface and as such were selected for the roughness evaluation. Therefore, only the $R_{\mathrm{a}}$ and $R_{\mathrm{z}}$ were discussed and analyzed in this study.

\section{Determination of the contact angle and surface free energy}

The samples of control, heat treatment at a temperature of $180{ }^{\circ} \mathrm{C}$, resin impregnation, and impregnation combined with heat treatment at 3 different temperatures were respectively processed into a size of $50 \mathrm{~mm} \times 50 \mathrm{~mm} \times 20 \mathrm{~mm}, 3$ samples for each group, a total of 18 samples. The contact angle test reagents were distilled water (polar liquid) and diiodomethane (non-polar liquid). The contact angle of each liquid drop on the tangential surface was measured using an optical contact angle instrument (Theta Lite, 
Biolin Scientific, Gothenburg, Sweden). A micro-injector was used to take $2 \mu \mathrm{L}$ and drop it on the planed surface. The contact angle was measured within $2 \mathrm{~s}$ after the droplet dropped onto the surface of the sample. Each sample was measured 4 times for each liquid with different measurement positions. The initial contact angle, i.e., the contact angle when the droplet contacted the wood surface, was recorded and the average value was calculated. After the measurement, the surface droplets were removed with absorbent paper. After obtaining the contact angle value of $\theta$, the Owens double-liquid method (Owens and Wendt 1969) was used to calculate the surface free energy. According to the polar force $\left(\gamma_{s p}\right)$, the dispersion force $\left(\gamma_{\mathrm{s} d}\right)$ (non-polar force), and the surface free energy $\left(\gamma_{\mathrm{s}}\right)$ (surface tension) of distilled water and diiodomethane (Table 1) and the contact angle value of $\theta$, the polar force and the dispersion force $\left(\gamma_{\mathrm{Ld}}\right)$ can be obtained from Eq. 5 and 6, respectively,

$$
\begin{aligned}
& \gamma_{L_{1}}\left(1+\cos \theta_{1}\right)=2\left(\gamma_{S} d \gamma_{L_{1}}{ }^{1 / 2}+2\left(\gamma_{S} p{\gamma_{L_{1}}}\right)^{1 / 2}\right. \\
& \gamma_{L_{2}}\left(1+\cos \theta_{2}\right)=2\left(\gamma_{S} d \gamma_{L_{2}}{ }^{1 / 2}\right)^{1 / 2}+2\left(\gamma_{S} p \gamma_{L_{2}} p\right)^{1 / 2}
\end{aligned}
$$

and then the surface free energy $\left(\gamma_{\mathrm{L}}\right)$ can be obtained according to Eq. 7,

$$
\gamma_{s} d+\gamma_{s} p=\gamma_{s}
$$

where $\gamma_{\mathrm{L}}, \gamma_{\mathrm{Ld}}$, and $\gamma_{\mathrm{Lp}}$ are the surface tension, dispersion force, and polar force of the test liquid (distilled water and diiodomethane), respectively, $\gamma_{\mathrm{s}}, \gamma_{\mathrm{s} d}, \gamma_{\mathrm{s} p}$ and are the surface free energy, dispersion force, and polar force of the test wood samples, respectively, and $\theta$ is the contact angle.

Table 1. Surface Tension, Polar Force, and Non- Polar Force of the Test Liquid

\begin{tabular}{|c|c|c|c|c|}
\hline Test Liquid & Type & $\begin{array}{c}\text { Dispersion Force } \\
\gamma_{L d}\left(\mathrm{~mJ} / \mathrm{m}^{2}\right)\end{array}$ & $\begin{array}{c}\text { Polar Force } \\
\gamma_{L p}\left(\mathrm{~mJ} / \mathrm{m}^{2}\right)\end{array}$ & $\begin{array}{c}\text { Surface Tension } \\
\gamma_{L}\left(\mathrm{~mJ} / \mathrm{m}^{2}\right)\end{array}$ \\
\hline Distilled water & Polar & 21.80 & 51.00 & 72.80 \\
\hline Diiodomethane & Non-polar & 48.50 & 2.30 & 50.80 \\
\hline
\end{tabular}

\section{RESULTS AND DISCUSSION}

\section{Color of Modified Materials}

Figure 1 shows the colors of the control and the modified samples. The HT at a temperature of $180{ }^{\circ} \mathrm{C}$ for $3 \mathrm{~h}$ drastically increased the darkness of specimens, while the IMPG changed the surface color to light yellow. The color of the IMPG+HT samples changed considerably with different heat treatment temperatures. As the heat treatment temperature increased, the color gradually changed from light yellow to brown and dark brown. By comparing Fig. 1b and Fig. 1e, it was found that, with the same heat treatment temperature and duration, i.e., $180{ }^{\circ} \mathrm{C}$ and $3 \mathrm{~h}$, the color of the HT sample was darker than the color of the IMPG+HT at a temperature of $180{ }^{\circ} \mathrm{C}$, which indicated that the resin impregnation had a certain inhibitory effect on the color change of the wood. 


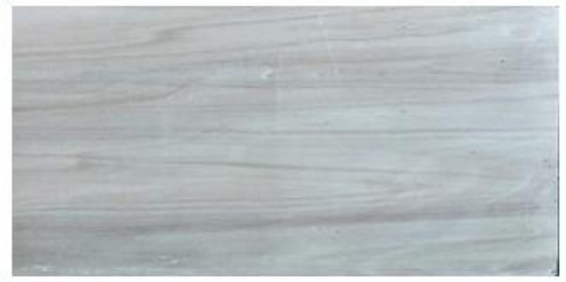

(a) Control

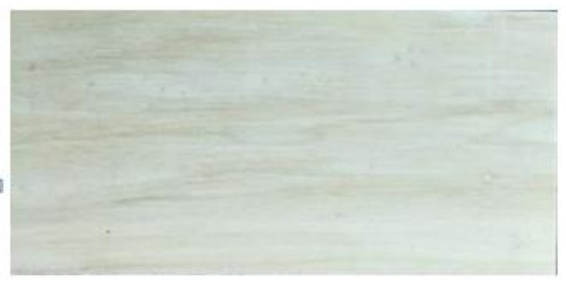

(c) IMPG

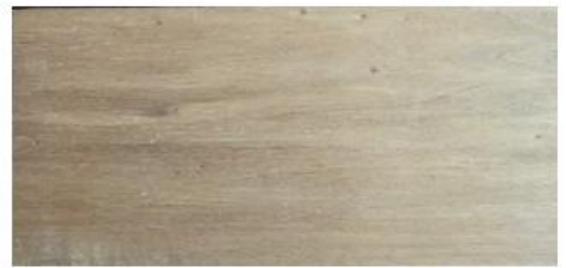

(e) IMPG+HT $180^{\circ} \mathrm{C}$

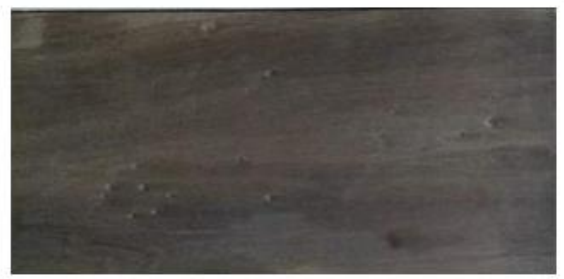

(b) $\mathrm{HT}$

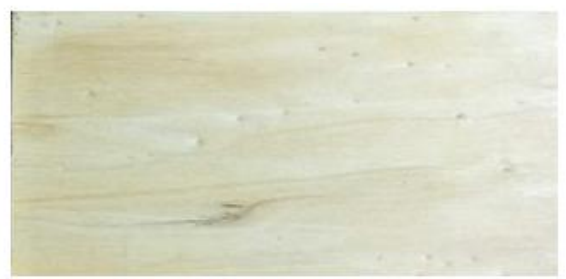

(d) IMPG+HT $160^{\circ} \mathrm{C}$

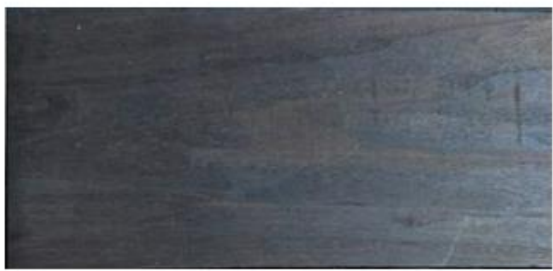

(f) IMPG+HT $200^{\circ} \mathrm{C}$

Fig. 1. Surface colors of the different samples

Table 2 shows the results of the color index and their changes after different modifications. As can be seen from Table 2, the $L^{*}$ of the HT samples was 40.97, which was $38.18 \%$ lower than the $L^{*}$ of the control, which indicated the lightness of poplar wood decreased after the heat treatment (Militz 2002). The lightness of the IMPG samples slightly decreased (1.37\%), which indicated that the resin impregnation had a minor effect on the lightness value of poplar. After the IMPG+HT, the $L^{*}$ value ranged from 33.76 to 66.23 , and the lightness values were $14.63 \%$ to $56.49 \%$ lower than the lightness of the control. This was attributed to the fact that the water-soluble UF resin itself was yellowish brown. After being immersed in the wood and cured by heating, the color became darker. In addition, it contained hydroxyl (-OH), which was easy to change after the HT treatment, forming benzoquinone or other structures and causing the color of the samples to deepen. As the heat treatment temperature increased, the lightness value of the IMPG+HT samples became lower, and the color became darker. This was primarily due to the fact that the higher the heat treatment temperature, the more obvious the degradation of the hemicellulose and impregnated resin, and these dark degradation products led to the decrease in the wood lightness. With the same heat treatment process $\left(180{ }^{\circ} \mathrm{C}\right.$ and $\left.3 \mathrm{~h}\right)$, the lightness of the HT samples more considerably decreased compared to the IMPG+HT samples. This may be due to the crosslinking of the resin and hemicelluloses in the wood, which inhibited the degradation to some extent, or the alkaline environment caused by the urea-formaldehyde resin inhibited the degradation of the hemicelluloses, thereby decreasing the effect of the heat treatment on the lightness reduction (Zhang et al. 2014). 
Table 2. Changes in the Color Indexes of the Control and Modified Samples

\begin{tabular}{|c|c|c|c|c|c|c|}
\hline Materials & $L^{*}$ & $\Delta L^{*}$ & $a^{*}$ & $\Delta a^{*}$ & $b^{*}$ & $\Delta b^{*}$ \\
\hline Control & 77.59 & - & 4.71 & - & 20.99 & - \\
\hline $\mathrm{HT}\left(180^{\circ} \mathrm{C}\right)$ & $40.97(2.01)$ & -36.62 & $8.10(0.50)$ & 3.39 & $17.19(1.11)$ & -3.80 \\
\hline IMPG & $76.53(2.77)$ & -1.06 & $4.08(0.94)$ & -0.63 & $28.48(1.61)$ & 7.49 \\
\hline $\begin{array}{c}\text { IMPG+HT 160 } \\
{ }^{\circ} \mathrm{C}\end{array}$ & $66.23(3.26)$ & -11.36 & $8.92(0.92)$ & 4.21 & $36.42(1.91)$ & 15.43 \\
\hline $\begin{array}{c}\text { IMPG }+\mathrm{HT} 180 \\
{ }^{\circ} \mathrm{C}\end{array}$ & $53.17(3.41)$ & -24.42 & $10.63(0.61)$ & 5.92 & $28.64(2.18)$ & 7.65 \\
\hline $\begin{array}{c}\text { IMPG+HT } 200 \\
{ }^{\circ} \mathrm{C}\end{array}$ & $33.76(2.24)$ & -43.83 & $7.20(0.95)$ & 2.49 & $13.88(2.22)$ & -7.11 \\
\hline
\end{tabular}

Note: the data in the parenthesis refers to the standard deviations

The $a^{*}$ of the HT samples increased by $71.97 \%$ compared to the $a^{*}$ of the control, which indicated that the HT increased the red-green index of the poplar wood. The $a^{*}$ of the IMPG samples decreased by $13.38 \%$, which indicated that the IMPG treatment reduced the red-green index of the poplar wood. The $a^{*}$ of the IMPG+HT samples ranged from 7.20 to 10.63 , which increased by $52.87 \%$ to $125.69 \%$ when compared to the control. As the HT temperature increased, the $a^{*}$ first increased and then decreased. However, the $a^{*}$ value of the IMPG+HT was always higher than the $a^{*}$ value of the control and IMPG samples.

With the same heat treatment process $\left(180{ }^{\circ} \mathrm{C}\right.$ and $\left.3 \mathrm{~h}\right)$, the $a^{*}$ of the IMPG+HT increased more than the $a^{*}$ of the HT samples, and its color was more reddish. This may be due to the resin and lignin crosslinking at this temperature, which changed the number of chromophoric groups, e.g., carbonyl groups in lignin (Zor et al. 2019). When the temperature was higher than $180{ }^{\circ} \mathrm{C}$, the product generated by the crosslinking of the resin and lignin was unstable and further degraded into small molecules at high temperatures, leading to an increase then decrease of the $a^{*}$ as the temperature increased (Raisanen et al. 2003).

The $b^{*}$ values of the HT samples were $18.10 \%$ lower than the $b^{*}$ of the control, which indicated a reduction of the yellow-blue index of poplar wood after the HT. The $b^{*}$ of the IMPG samples increased by $65.68 \%$, which indicated an increase in the yellow-blue index of poplar after the IMPG treatment. The $b^{*}$ of the IMPG+HT samples ranged from 13.88 to 36.42 , which increased by $-33.87 \%$ to $73.51 \%$ when compared to the control. As the heat treatment temperature increased, the $b^{*}$ value gradually decreased, even eventually reaching a negative $\Delta b^{*}$ value. This was because there was no obvious resin degradation, and its color was still yellowish at lower heat treatment temperatures. However, as the temperature increased, the resin degradation became more obvious, which resulted in a rapid decrease in the $\Delta b^{*}$. With the same heat treatment process $\left(180{ }^{\circ} \mathrm{C}\right.$ and $\left.3 \mathrm{~h}\right)$, the changes in the $\Delta b^{*}$ of the HT samples and the IMPG+HT were opposite, which was primarily affected by the addition of resin.

Figure 2 shows the color differences of the samples from different modification groups. The total colour difference of each modified group are given in descending order as follows: IMPG+HT $20{ }^{\circ} \mathrm{C}$ was greater than $\mathrm{HT}$, which was greater than IMPG+HT 180 ${ }^{\circ} \mathrm{C}$, which was greater than IMPG+HT $160^{\circ} \mathrm{C}$, which was greater than IMPG. The total color difference between the IMPG and the control was small. However, the HT had major impact on the absolute color difference. The $\Delta E$ of the IMPG+HT samples ranged from 
19.62 to 44.47. The higher the heat treatment temperature, the greater the $\Delta E$. When the temperature was higher than $180^{\circ} \mathrm{C}$, there was a drastic increase in the $\Delta E$. With the same heat treatment process $\left(180^{\circ} \mathrm{C}\right.$ and $\left.3 \mathrm{~h}\right)$, the total color difference between the combined modified samples and the controls was smaller than the total color difference of the heat treatment, which indicated that the impregnation pretreatment can effectively reduce the effect of the heat treatment on the color.

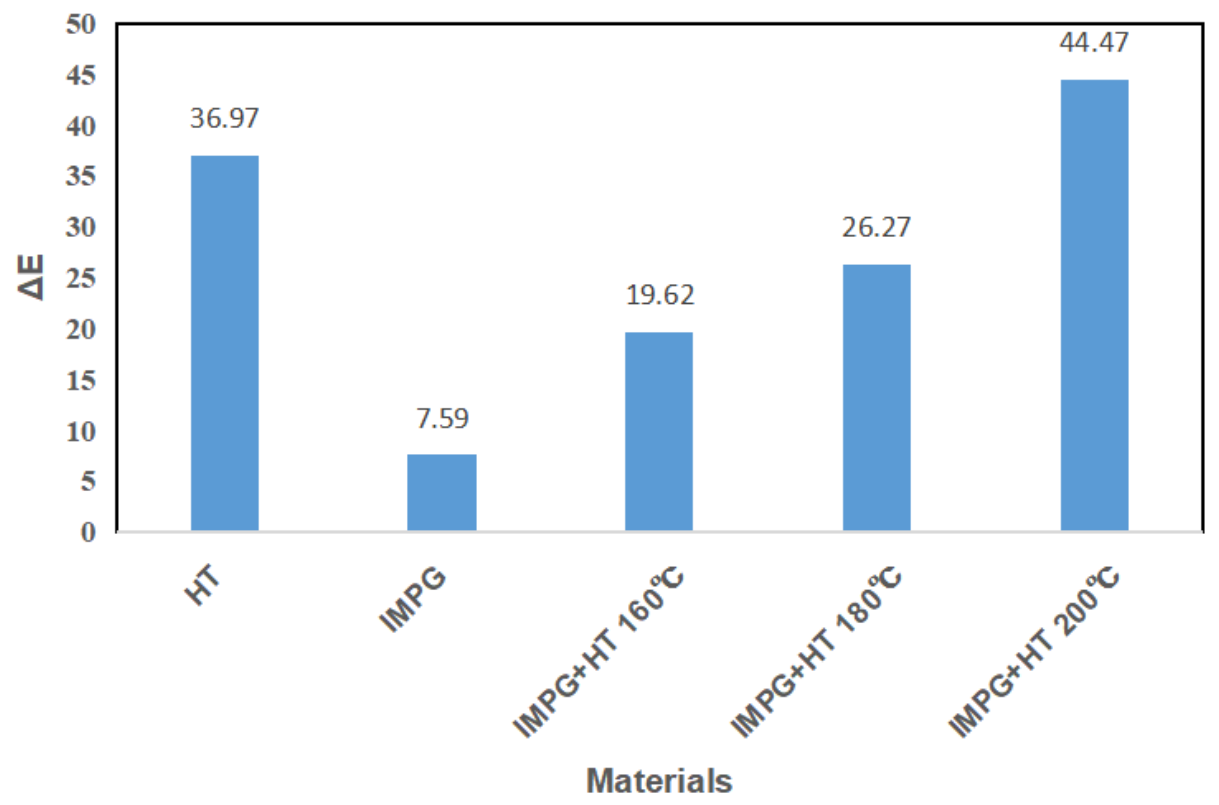

Fig. 2. Color difference values of the different samples

\section{Surface Roughness of the Modified Woods}

Figure 3 shows the surface profile of each test group after sanding. Figures 4 and 5 show the test results of the $R_{\mathrm{a}}$ and $R_{\mathrm{z}}$ of each group, respectively.

Figure 3 shows that the surface of the control was relatively flat. After the resin impregnation process, heat treatment, or combined modification, the $R_{\mathrm{a}}$ and $R_{\mathrm{z}}$ values became larger, and the wood surface became rougher than the control. Heat treatment made the wood more brittle and easier to crack during cutting; the impregnated resin was plasticized, and the heat generated by sanding caused the plasticized resin to fluff during the sanding process. According to Figs. 4 and 5, the $R_{\mathrm{a}}$ and $R_{\mathrm{z}}$ values of the planed wood surface were larger than the $R_{\mathrm{a}}$ and $R_{\mathrm{z}}$ values of the sanded wood. This was because the wood surface processing method is an important factor in terms of its surface roughness. The higher the processing accuracy, the lower the surface roughness (Wang et al. 2005). However, for both the sanded and planed surfaces, the $R_{\mathrm{a}}$ had similar trends after different modification treatments.

Both the $R_{\mathrm{a}}$ and $R_{\mathrm{z}}$ values of poplar wood increased after HT. After the planing process, the $R_{\mathrm{a}}$ and $R_{\mathrm{z}}$ increased from 6.15 and $40.39 \mu \mathrm{m}$ to 7.16 and $46.32 \mu \mathrm{m}$, respectively. After the sanding process, $R_{\mathrm{a}}$ and $R_{\mathrm{z}}$ increased from 3.63 and $25.06 \mu \mathrm{m}$ to 4.57 and $29.30 \mu \mathrm{m}$, respectively. These results showed that the surface of the poplar wood became more uneven after HT at a temperature of $180{ }^{\circ} \mathrm{C}$ for $3 \mathrm{~h}$, which agreed with the results reported by Bakar et al. (2013). The reason for the increased surface roughness in poplar wood after HT might be due to the breakages of fibers of the heat-treated wood 
during the planing and sanding processes (Bourmaud and Baley 2009; Butylina et al. 2011). Therefore, the surface of the wood fibers split, and the surface roughness increased.

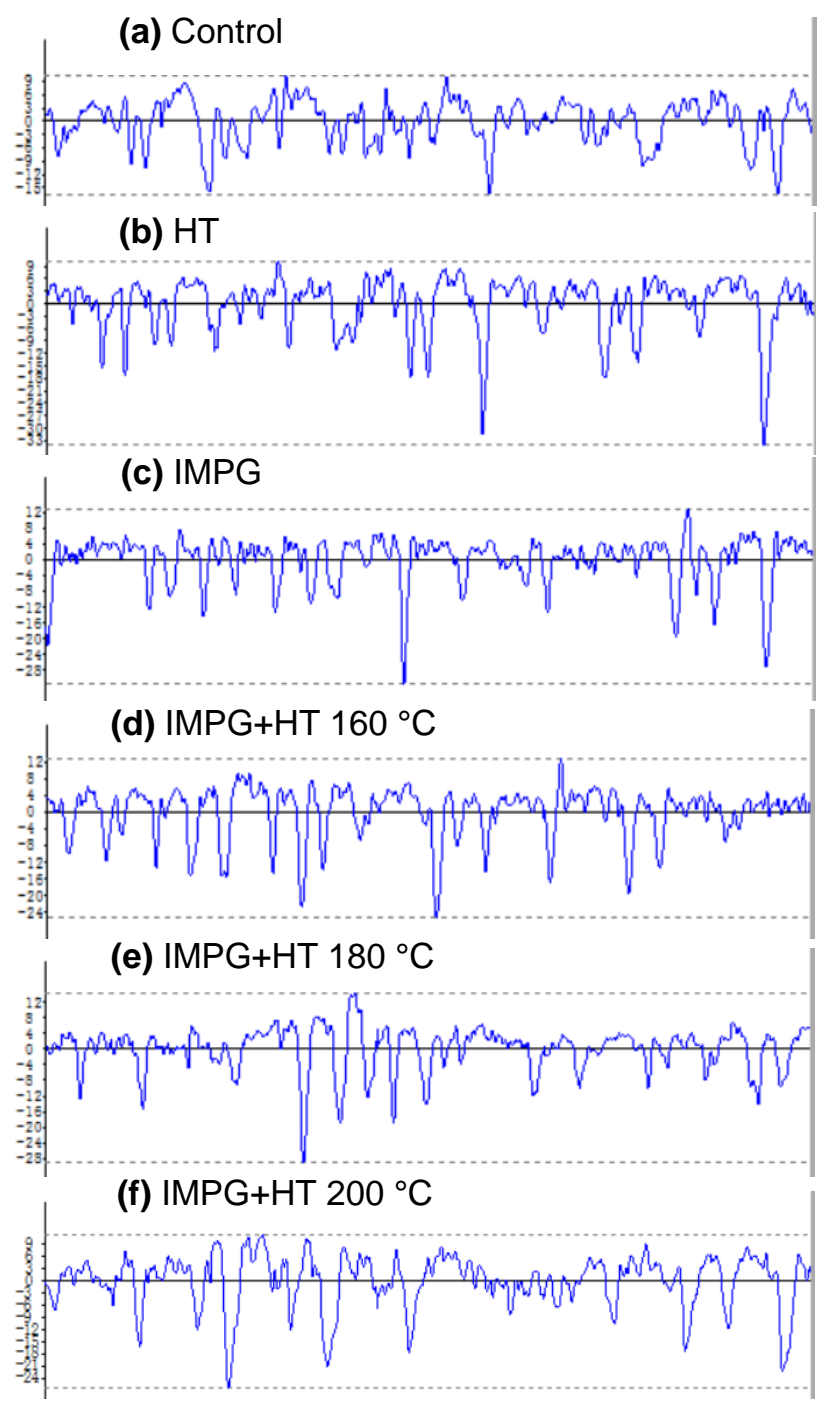

Fig. 3. Surface roughness profile of the different test woods after sanding

The results also showed that both the $R_{\mathrm{a}}$ and $R_{\mathrm{z}}$ values increased after IMPG. After the planing process, the $R_{\mathrm{a}}$ and $R_{\mathrm{z}}$ increased to 7.61 and $52.12 \mu \mathrm{m}$, respectively. After the sanding process, the $R_{\mathrm{a}}$ and $R_{\mathrm{z}}$ increased to 4.21 and $28.97 \mu \mathrm{m}$, respectively. The result showed that the resin impregnation also improved the surface roughness of poplar wood. The primary reason for this result might be that the uneven distribution of the resin in the microstructure of the wood increased the roughness of wood.

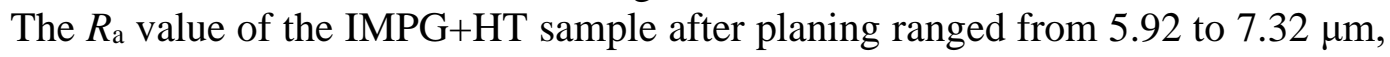
while the $R_{\mathrm{z}}$ value ranged from 37.96 to $47.98 \mu \mathrm{m}$. After the sanding process, the $R_{\mathrm{a}}$ and $R_{\mathrm{z}}$ values decreased from 3.76 to $4.46 \mu \mathrm{m}$ and 25.95 to $28.16 \mu \mathrm{m}$, respectively. As shown in Figs. 4 and 5, the $R_{\mathrm{a}}$ and $R_{\mathrm{z}}$ of the IMPG+HT samples first decreased and then increased as the heat treatment temperature increased. The surface roughness of the IMPG+HT samples at $160^{\circ} \mathrm{C}$ had no considerable difference from the IMPG samples, and the surface 
of the IMPG+HT sample at $180{ }^{\circ} \mathrm{C}$ was the smoothest. This might be because the volume of the impregnated resin shrunk at a temperature of $180{ }^{\circ} \mathrm{C}$, which led to the resin filling in the vessels, and the wood fibers tending to be flat, thus reducing the effect of the resin on the surface roughness (Eichhorn et al. 2001). However, when the heat treatment temperature reached $200{ }^{\circ} \mathrm{C}$, the resin degradation products and the wood extracts migrated to the wood surface, which resulted in an increase in the surface roughness of the IMPG+HT wood at a temperature of $200{ }^{\circ} \mathrm{C}$ (Willner and Brunner 2005; Poletto 2016).

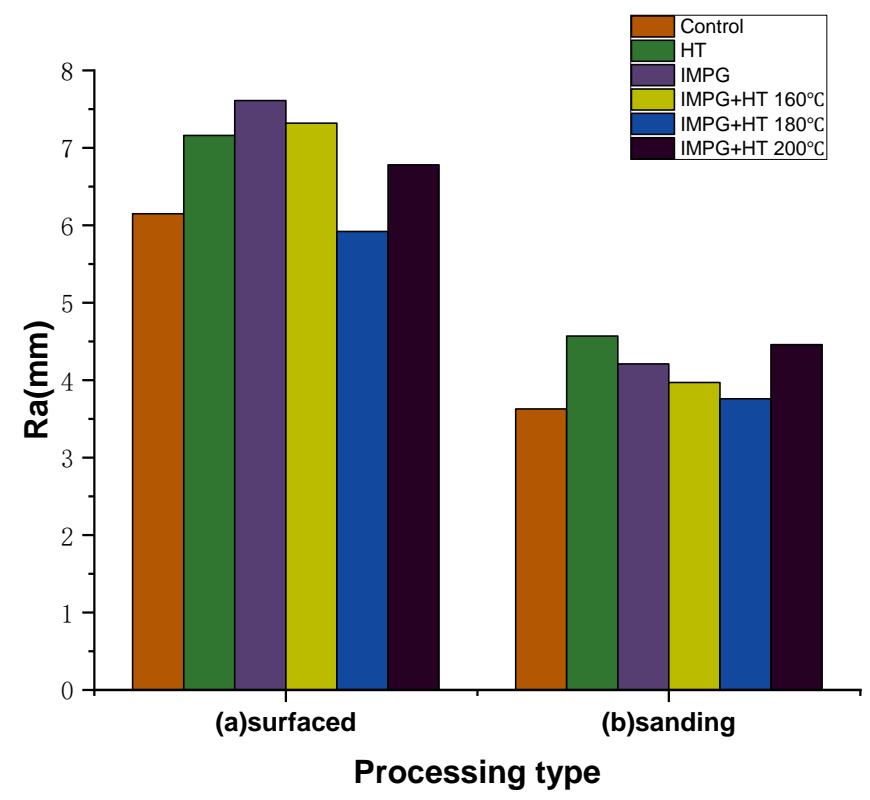

Fig. 4. $R_{a}$ of the different test woods

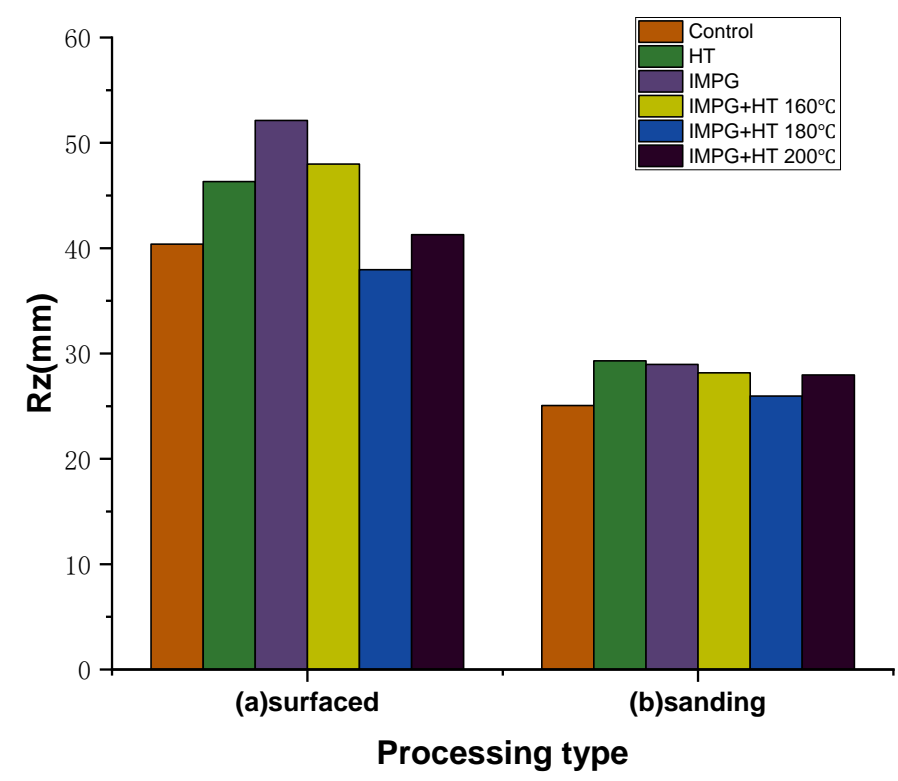

Fig. 5. $R_{\mathrm{z}}$ of the different test woods 


\section{Surface Wettability of the Modified Woods}

Figure 6 shows the initial contact angles of the poplar wood surface with distilled water and diiodomethane. The contact angle of diiodomethane on the wood surface was smaller than the contact angle of distilled water. The diiodomethane quickly wetted the wood at the moment of contact with the wood surface, but the outline of the droplet on the wood surface was still clear. Then, the droplet was gradually absorbed by the wood. This is because diiodomethane is a non-polar liquid, while distilled water has strong polarity and surface tension; therefore, the contact angle between the wood surface and distilled water was larger (Fabiyi and McDonald 2010).

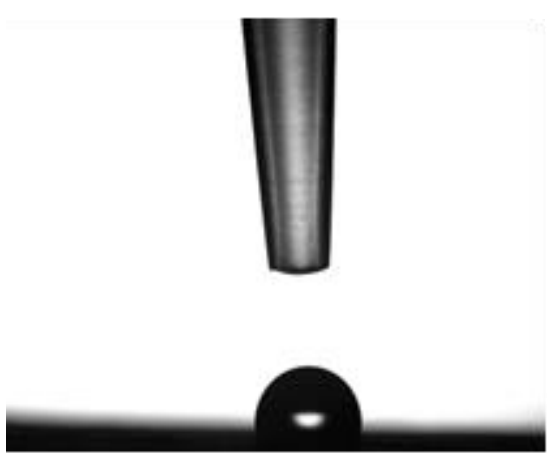

(a) distilled water

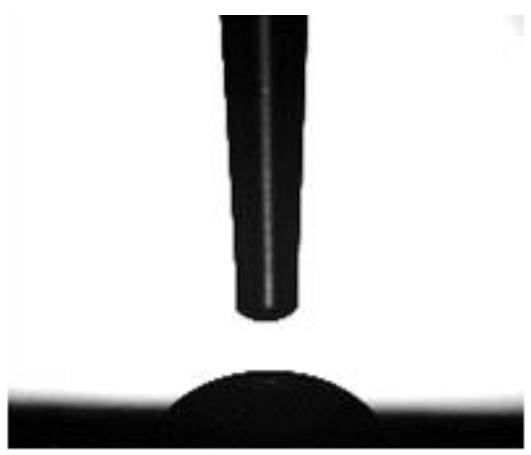

(b) diiodomethane

Fig. 6. Initial contact angle of poplar wood with distilled water and diiodomethane

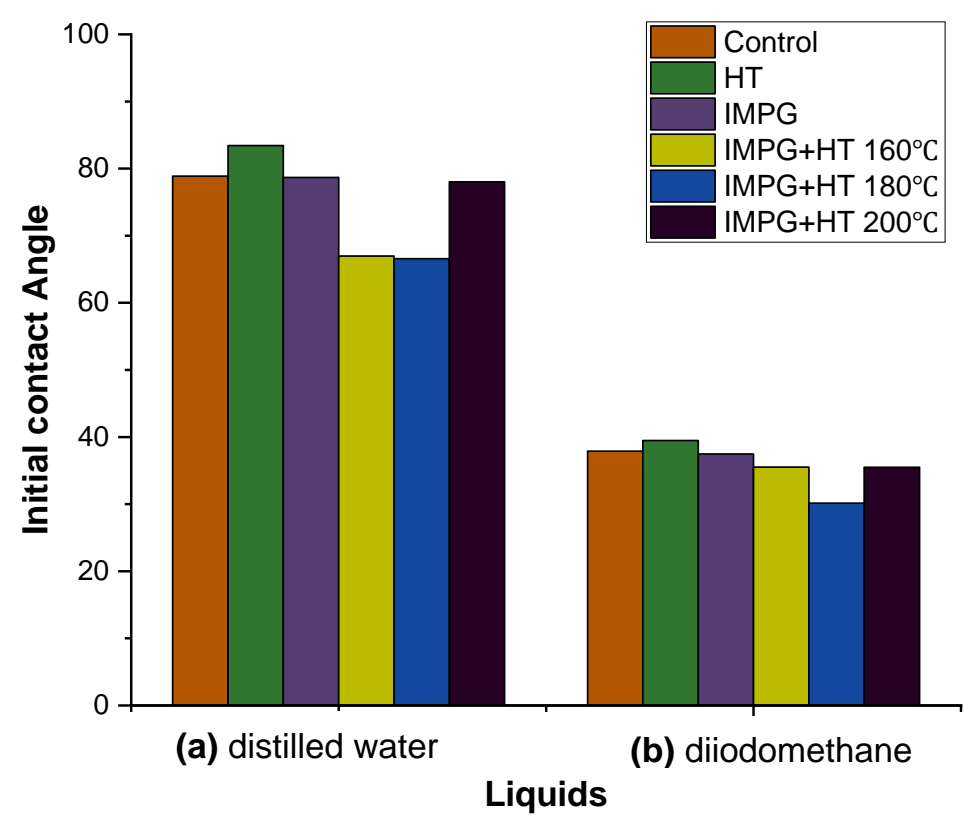

Fig. 7. Initial contact angles of the different test wood samples with distilled water and diiodomethane

Figure 7 shows the results of the contact angles of the different test groups with distilled water and diiodomethane. The contact angle of distilled water on the surface of the samples in descending order was as follows: HT was greater than Control, which was 
greater than IMPG, which was greater than IMPG+HT $200{ }^{\circ} \mathrm{C}$, which was greater than IMPG+HT $160{ }^{\circ} \mathrm{C}$, which was greater than IMPG+HT $180{ }^{\circ} \mathrm{C}$. Among all groups, the HT sample had the largest contact angle $\left(83.43^{\circ}\right)$, which indicated that the hydrophobicity was increased after HT treatment. This was attributed to a decrease in the number of hydrophilic groups on the wood surface, caused by the degradation of hemicellulose during the HT treatment. The contact angle of the poplar wood with distilled water slightly decreased from $78.87^{\circ}$ to $78.69^{\circ}$ after impregnation, which indicated that the IMPG treatment had little effect on the hydrophilicity. The contact angle between the IMPG+HT wood and distilled water, which ranged from $66.57^{\circ}$ to $78.02^{\circ}$, first decreased and then increased as the heat treatment temperature increased. This might be due to the fact that the HT did not drastically degrade the wood components and had a limited effect on increasing the hydrophobicity at the lower temperature. However, the resin preferentially degraded and produced hydrophilic degradation products during the low-temperature HT (Mankowski and Morrell 2000; Verhey et al. 2001; Tripathi et al. 2014). Such a phenomenon predominantly influenced the contact angle and led to the decreased contact angle and increased wettability of the IMPG+HT samples when the wood was heat-treated below 200 ${ }^{\circ} \mathrm{C}$. When the temperature reached $200{ }^{\circ} \mathrm{C}$, the HT had a noticeable degradation effect on the wood components, and the hydrophilic groups on the wood surface were drastically reduced. Therefore, the influence of the HT on the contact angle was dominant, which made the hydrophobicity of the IMPG+HT samples increase.

The contact angle of diiodomethane on the surface of the samples in descending order was as follows: HT was greater than Control, which was greater than IMPG, which was greater than IMPG+HT $200{ }^{\circ} \mathrm{C}$, which was greater than IMPG+HT $160{ }^{\circ} \mathrm{C}$, which was greater than IMPG+HT $180{ }^{\circ} \mathrm{C}$, which was consistent with the results of distilled water. The contact angle of diiodomethane on the surface of the HT sample was the largest $\left(39.47^{\circ}\right)$, which indicated that the oleophobicity was increased after the HT treatment. After the heat treatment, the number of lipophilic groups decreased. $180{ }^{\circ} \mathrm{C}$ heat treatment had the greatest tendency to bring alkyl-type monomers to the wood surface such as fatty acids. Such materials would have a relatively low Hamaker constant, thus tending to give a relatively low dispersion-type interaction energy with the nonpolar probe liquid. The contact angle of the IMPG sample was slightly reduced. The reduction from $37.90^{\circ}$ to $37.46^{\circ}$ indicated that the resin had little effect on the lipophilicity. The contact angle of the IMPG+HT wood sample with diiodomethane ranged from $30.14^{\circ}$ to $35.53^{\circ}$, which also first decreased and then increased as the HT temperature increased, due to the same reason as the change in contact angle of distilled water.

Table 3 shows the surface free energy and its component results of the different modified samples.

Table 3. Surface Free Energy and Component Value of Different Specimens

\begin{tabular}{|c|c|c|c|}
\hline Materials & $\begin{array}{c}\text { Dispersion Force } \gamma_{\mathrm{sd}} \\
\left(\mathrm{mJ} / \mathrm{m}^{2}\right)\end{array}$ & $\begin{array}{c}\text { Polar Force } \gamma_{\mathrm{sp}} \\
\left(\mathrm{mJ} / \mathrm{m}^{2}\right)\end{array}$ & $\begin{array}{c}\text { Surface Tension } \gamma_{\mathrm{s}} \\
\left(\mathrm{mJ} / \mathrm{m}^{2}\right)\end{array}$ \\
\hline Control & 36.78 & 4.48 & 41.26 \\
\hline $\mathrm{HT}$ & 37.13 & 2.88 & 40.01 \\
\hline $\mathrm{IMPG}$ & 36.97 & 4.50 & 41.47 \\
\hline $\mathrm{IMPG}+\mathrm{HT} 160^{\circ} \mathrm{C}$ & 35.54 & 9.36 & 44.90 \\
\hline $\mathrm{IMPG}+\mathrm{HT} 180^{\circ} \mathrm{C}$ & 37.47 & 9.47 & 47.21 \\
\hline $\mathrm{IMPG}+\mathrm{HT} 200^{\circ} \mathrm{C}$ & 37.83 & 4.55 & 42.38 \\
\hline
\end{tabular}


As shown in Table 3, the surface free energy of the different modified samples in descending order was as follows: IMPG+HT $180^{\circ} \mathrm{C}$ was greater than IMPG+HT $160{ }^{\circ} \mathrm{C}$, which was greater than IMPG+HT $200{ }^{\circ} \mathrm{C}$, which was greater than IMPG, which was greater than Control, which was greater than HT, which was the result of the contact angle in contrast. After the heat treatment, the dispersion force (non-polar component) changed from $36.78 \mathrm{~mJ} / \mathrm{m}^{2}$ to $37.13 \mathrm{~mJ} / \mathrm{m}^{2}$, and the polar force (polar component) changed from $4.48 \mathrm{~mJ} / \mathrm{m}^{2}$ to $2.88 \mathrm{~mJ} / \mathrm{m}^{2}$. This was due to the increase of the number of non-polar functional groups on the wood surface and the decrease of the number of polar functional groups (hydroxyl) through the heat treatment. The surface free energy of the IMPG and its components were slightly increased compared to the control, which indicated that the impregnation had no obvious influence on the wettability of the wood. After the IMPG was heat-treated at different temperatures, its surface free energy changed according to the temperature. Compared with the IMPG samples, the dispersion force of the IMPG- $160{ }^{\circ} \mathrm{C}$ sample was reduced by $3.87 \%$, and the polar force was obviously increased (the increase rate was as high as $108.00 \%$ ), which indicated that the heat treatment temperature reduced the number of non-polar functional groups in the IMPG samples, and the number of polar functional groups considerably increased. As the heat treatment temperature increased, the dispersion force of the impregnation combined heat treatment samples gradually increased, while the polar force first increased and then decreased as the heat treatment temperature increased. However, the surface free energy of the impregnation combined heat treatment samples at all three temperatures were higher than the surface free energy of the IMPG samples, which indicated that the heat treatment improved the wettability of the IMPG samples. Among them, the sample after the IMPG+HT $180{ }^{\circ} \mathrm{C}$ treatment had the largest surface free energy and the good wettability.

\section{CONCLUSIONS}

1. In this study, the color, surface roughness, and surface wettability of the untreated control wood, and the wood modified via heat treatment, resin impregnation, and impregnation combined heat treatment (at $160{ }^{\circ} \mathrm{C}, 180{ }^{\circ} \mathrm{C}$, and $200{ }^{\circ} \mathrm{C}$ ) were investigated. The results showed that the lightness $\left(L^{*}\right)$ values of each group were ranked as follows: Control was greater than resin impregnation plus heat treatment (IMPG+HT) $200{ }^{\circ} \mathrm{C}$, which was greater than $\mathrm{HT}$, which was greater than IMPG+HT $180{ }^{\circ} \mathrm{C}$, which was greater than IMPG+HT $160^{\circ} \mathrm{C}$, which was greater than IMPG. The wood surface turned a reddish color after HT and IMPG+HT, while it became a greenish color after the IMPG treatment. For the IMPG+HT wood, the color became darker and more blueish as the heat treatment temperature increased. Simultaneously, the reddish color first increased and then decreased, and the total color change always increased as the temperature increased. The IMPG treatment had a small effect on the total color change, while the HT had a major impact on the total color change.

2. Both the HT and IMPG treatments increased the surface roughness of the wood. The $R_{\mathrm{a}}$ and $R_{\mathrm{z}}$ of the IMPG+HT wood samples first decreased and then increased as the heat treatment temperature increased. The surface roughness of the IMPG+HT wood samples at a temperature of $160{ }^{\circ} \mathrm{C}$ were not considerably different from the surface roughness of the IMPG wood samples. The surface of the IMPG+HT wood at a temperature of $180{ }^{\circ} \mathrm{C}$ was the smoothest among all the groups, while the surface 
roughness of the IMPG+HT samples at a temperature of $200{ }^{\circ} \mathrm{C}$ began to increase. The results showed that both the $R_{\mathrm{a}}$ and $R_{\mathrm{z}}$ increased after different modifications.

3. The initial contact angles of all test groups with distilled water were greater than the initial contact angles with diiodomethane. The contact angle of distilled water on the surface of the samples in descending order are as follows: HT was greater than Control, which was greater than IMPG, which was greater than IMPG+HT $200{ }^{\circ} \mathrm{C}$, which was greater than IMPG+HT $160{ }^{\circ} \mathrm{C}$, which was greater than IMPG+HT $180{ }^{\circ} \mathrm{C}$. After the heat treatment, the polar component and surface free energy were reduced, and the wettability was reduced. After impregnation, the surface free energy and its components were slightly increased. Compared with the other modified samples, the surface free energy of the IMPG+HT samples increased, and the wettability was improved. Among them, the polar components of the samples after the IMPG+HT 160 ${ }^{\circ} \mathrm{C}$ and IMPG+HT $180{ }^{\circ} \mathrm{C}$ treatments were obviously higher than the polar components of the IMPG samples, but the polar component of IMPG+HT $200{ }^{\circ} \mathrm{C}\left(4.55 \mathrm{~mJ} / \mathrm{m}^{2}\right)$ was reduced to close to the value of the polar component of IMPG $\left(4.48 \mathrm{~mJ} / \mathrm{m}^{2}\right)$.

\section{ACKNOWLEDGMENTS}

The authors acknowledge the Fuyang Jinmu Arts and Crafts Co. Ltd. for providing research materials and processing equipment. Additional thanks go for the Nanjing Forestry University Advanced Analysis and Testing Centre for testing services. The authors also acknowledge Prof. Jiabin Cai for his helpful advice and critical reading of the manuscript.

\section{REFERENCES CITED}

Bakar, B. F. A., Hiziroglu, S., and Tahir, P. (2013). "Properties of some thermally modified wood species," Materials \& Design 43, 348-355. DOI: 10.1016/j.matdes.2012.06.054

Baysal, E., Degirmentepe, S., Toker, H., Sitki, M., and Turkoglu, T. (2014). "Some mechanical and physical properties of AD-KD 5 impregnated and thermally modified scots pine wood," Wood Research 59(2), 283-296.

Bourmaud, A., and Baley, C. (2009). "Rigidity analysis of polypropylene/vegetal fibre composites after recycling," Polymer Degradation and Stability 94(3), 297-305. DOI: 10.1016/j.polymdegradstab.2008.12.010

Butylina, S., Martikka, O., and Kärki, T. (2011). "Physical and mechanical properties of wood polypropylene composites made with virgin and/or recycled polypropylene," Polymer-Plastics Technology and Engineering 50(10), 1040-1046. DOI: 10.1080/03602559.2011.557823

Cai, C., Haapala, A., Rahman, M. H., Tiitta, M., Tittia, V., and Heräjärvi, H. (2020). "Effect of 2-year natural weathering on chemical and physical properties of thermally modified Picea abies, Pinus sylvestris and Fraxinus excelsior wood," Canadian Journal of Forest Research 50, 1160-1171. DOI: 10.1139/cjfr-2019-0446 
Ding, T., Peng, W., and Li, T. (2017). "Mechanism of color change of heat-treated white ash wood by means of FT-IR and XPS analyses," China Forestry Science and Technology 2(5), 25-30. DOI: 10.13360/j.issn.2096-1359.2017.05.005

Eichhorn, S. J., Baillie, C. A., Zafeiropoulos, N., Mwaikambo, L. Y., Ansell, M. P., Dufresne, A., Entwistle, K. E., Herrera-Franco, P. J., Escamillia, G. C., Groom, L., et al. (2001). "Review: Current international research into cellulosic fibres and composites," Journal of Material Science 36(9), 2107-2131. DOI: 10.1023/A:1017512029696

Fabiyi, J. S., and McDonald, A. G. (2010). "Physical morphology and quantitative characterization of chemical changes of weathered PVC/pine composites," Journal of Polymers and the Environment 18(1), 57-64. DOI: 10.1007/s10924-009-0152-9

GB/T 1031 (2009). "Geometrical product specifications (GPS) - Surface texture: Profile method - Surface roughness parameters and their values," Standardization Administration of China, Beijing, China.

GB/T 12472 (2003). "Geometrical product specifications (GPS) - Surface texture: Profile method - Surface roughness parameters and their values for wooden pieces," Standardization Administration of China, Beijing, China.

GB/T 14074 (2017). "Testing methods for wood adhesives and their resins," Standardization Administration of China, Beijing, China.

Huang, Y., Fei, B., Yu, Y., and Zhao, R. (2013). "Effect of modification with phenol formaldehyde resin on the mechanical properties of wood from Chinese fir," BioResources 8(1), 272-282. DOI: 10.15376/biores.8.1.272-282

Lahtela, V., and Kärki, T. (2016). "The influence of melamine impregnation and heat treatment on the fire performance of Scots pine (Pinus sylvestris) wood," Fire and Materials 40(5), 731-737. DOI: 10.1002/fam.2338

Liu, B., Wang, X., and Liu, J. (2013). "Changes in dimensional stability and mechanical properties of Eucalyptus pellita by melamine-urea-formaldehyde resin impregnation and heat treatment," European Journal of Wood Products 71(5), 557-562. DOI: 10.1007/s00107-013-0700-9

LY/T 2407 (2015) "General technical requirements for resin impregnated modified wood production," Standardization Administration of China, Beijing, China.

Mankowski, M., and Morrell, J. J. (2000). "Patterns of fungal attack in wood-plastic composites following exposure in a soil-block test," Wood and Fiber Science 32(3), 340-345.

Militz, H. (2002). "Thermal treatment of wood: European processes and their background," in: Proceedings of the $33^{\text {rd }}$ International Research Group on Wood Protection Scientific Conference, 12-17 May, Cardiff, Wales, United Kingdom.

Owens, D. K., and Wendt, R. C. (1969). "Estimation of the surface free energy of polymers," Journal of Applied Polymer Science 13(8), 1741-1747. DOI:

10.1002/app.1969.070130815

Poletto, M. (2016). "Effect of extractive content on the thermal stability of two wood species from Brazil," Maderas. Cienic y tecnología 18(3), 435-42. DOI: 10.4067/S0718-221X2016005000039

Qin, S., Lei, L., Li, J., and Li, X. (2015). "Physical and mechanical properties of rubber wood modified with UF resin by impregnation," China Forest Products Industry 42(4), 14-17. DOI: 10.19531/j.issn1001-5299.2015.04.004

Quan, P., Li, Y., Cao, M., Jiang, C., Liu, Y., Hu, J., and Li, X. (2017). “The effect of high temperature heat treatment on the mechanical strength of UF resin modified Chinese 
fir," Journal of Central South University of Forestry and Technology 37(12), 153158. DOI: $10.14067 / j . c n k i .1673-923 x .2017 .12 .024$

Räisänen, U., Pitkänen, I., Halttunen, H., and Hurtta, M. (2003). "Formation of the main degradation compounds from arabinose, xylose, mannose and arabinitol during pyrolysis," Journal of Thermal Analysis and Calorimetry 72(2), 481-488. DOI: 10.1023/A:1024557011975

Sandberg, D., Kutnar, A., and Mantanis, G. (2017). "Wood modification technologies A review," iForest - Biogeosciences and Forestry 10(6), 895-908. DOI: 10.3832/ifor2380-010

Sivrikaya, H., Tesařová, D., Jeřábková, E, and Can, A. (2019). “Color change and emission of volatile organic compounds from Scots pine exposed to heat and vacuumheat treatment," Journal of Building Engineering 26, 1-7. DOI: 10.1016/j.jobe.2019.100918

Tripathi, S., Pant, H., and Kashyap, A. K. (2014). "Decay resistance against Basidiomycetes fungi of heat-treated Pinus roxburghii and Mangifera indica wood," Journal of Tropical Forest Science 26(2), 203-207.

Turkay, T., Ergun, B., Mehmet, Y., Huseyin, P., Cevdet, S., Ihsan, K., and Hilmi, T. (2016). "Mechanical properties of impregnated and heat treated oriental beech wood," BioResources 11(4), 8285-8296. DOI: 10.15376/biores.11.4.8285-8296

Verhey, S. A., Laks, P. E., and Richter, D. L. (2001). "The effect of composition on the decay resistance of model wood fiber-thermoplastic composites," in: Proceedings of the $6^{\text {th }}$ International Conference on Wood fiber Plastic Composites, May 15-16, Madison, WI, pp. 79-86.

Wang, M., Wang, J., and Li, L. (2005). "Roughness and roughness sense of wood surface from different machining processes," Journal of Beijing Forestry University 27(1), 14-18. DOI: 10.3321/j.issn:1000-1522.2005.01.004

Willner, T., and Brunner, G. (2005). "Pyrolysis kinetics of wood and wood components," Chemical Engineering \& Technology 28(10), 1212-25. DOI: 10.1002/ceat.200500206

$\mathrm{Xu}, \mathrm{K} ., \mathrm{Lu}, \mathrm{J}$., Li, X., and Wu, Y. (2015). "The effect of high temperature heat treatment on the dimensional stability of poplar PF impregnated wood," Journal of Beijing Forestry University 37(9), 70-77. DOI: 10.13332/j.1000-1522.20150019

Zhang, Y., Mu, J., Li, S., and Zhao, Y. (2014). "Effect of UF resin and MUF resin on pyrolysis characteristics of eucalyptus," Journal of Beijing Forestry University 36(3), 130-135. DOI: 10.13332/j.cnki.jbfu.2014.03.021

Zor, M., Can, A., and Gardner, D. J. (2019). "Surface characterization of weathered and heat-treated wood-based composites reinforced by styrene maleic anhydride," Color Research and Application 44(6), 1017-1023. DOI: 10.1002/col.22417

Article submitted: July 12, 2021; Peer review completed: August 21, 2021; Revised version received: September 1, 2021; Accepted: September 22, 2021; Published:

September 27, 2021.

DOI: $10.15376 /$ biores.16.4.7562-7577 